\title{
Ensino coletivo de violão: possibilidades para a aprendizagem colaborativa e cooperativa em EAD*
}

\section{Teaching collective guitar: possibilities for collaborative and cooperative learning in distance}

\author{
Risaelma de Jesus Arcanjo Moura
}

\begin{abstract}
In this experience report I reflect about the guitar teaching together the undergraduate students in Music, EAD, UFRGS, the poles of St. Felix and Salvador-BA. Consider the interdisciplinary Integrator Seminar, guitar, has contemplated in its content, teaching methodology, collective, I realized that interactions between the participants have promoted the learning of collaboration and cooperation. Based on a brief literature review of the areas of Music Education and Distance Education, I tried to understand the proposal for teaching guitar at a distance supported by technological tools. The roles teacher's tutors were emphasized for their importance in this mode of teaching. Thus, the collective approach associated to the use of appropriate information technologies to teaching distance guitar, are essential for collaborative learning and cooperative.
\end{abstract}

Keywords: collective learning, guitar, collaboration, cooperation.

Resumo. No presente relato de experiência reflito sobre o ensino de violão realizado junto aos alunos da licenciatura em Música, EAD, da UFRGS, nos pólos de São Félix e Salvador-BA. Considerando que a interdisciplina Seminário Integrador, Violão, tem contemplado em seu conteúdo a metodologia do ensino coletivo, percebi que as interações entre os participantes têm promovido a aprendizagem por colaboração e cooperação. Com base em uma breve revisão bibliográfica das áreas de Educação Musical e Educação a Distância, busquei compreender a proposta do ensino de violão a distância apoiado pelas ferramentas tecnológicas. Os papéis dos professores tutores foram ressaltados pela sua relevância nesta modalidade de ensino. Assim, a abordagem coletiva associada ao uso de tecnologias da informação adequadas ao ensino de violão a distância são fundamentais para promover a aprendizagem colaborativa e cooperativa.

Palavras chave: ensino coletivo, violão, colaboração, cooperação.

\section{INTRODUÇÃO}

O violão brasileiro considerado como uma espécie de ícone da música nacional tardou a ocupar as salas de concerto e os programas oficiais de ensino. Contudo, tendo seu repertório 
ampliado ao longo das décadas, ressurgiu e se consolidou como um instrumento de suma importância para a carreira de amadores, concertistas e principalmente para a formação de professores dedicados ao ensino e aprendizagem do instrumento. Historicamente, os conservatórios são considerados os estabelecimentos mais tradicionais quanto ao ensino de violão, por terem suas práticas centradas em músicas de tradição européia. No entanto, mais recentemente esta realidade está se modificando, pois as pesquisas apontam que o ensino do instrumento tem sido pensado à luz de diferentes abordagens. Basta conferir alguns dos trabalhos dedicados a pedagogia do violão que dentre as quais destaco: Tourinho (1998), Queiroz (2000), Cruvinel (2001), Tiago e Perdomo (2004), Fireman (2006), Moura (2007), Barreto (2007), Santos e Mendes (2007).

Por outro lado, com o pronunciado avanço das Tecnologias da Informação e Comunicação (TICs) estudar violão se tornou uma realidade possível para muito mais pessoas. Este fato permite pensar que não há fronteiras de tempo e espaço para quem pretende aprender a tocar o instrumento utilizando as ferramentas tecnológicas disponíveis, para tanto basta que os usuários tenham acesso aos recursos da internet. Para Braga e Ribeiro (2007) "existe a necessidade de estreitamento da relação entre o ensino de instrumentos musicais e as tecnologias emergentes, e de fomentar as discussões acerca do professor de música com a mídia e as transformações sociais contemporâneas" (Braga; Ribeiro, 2007, p. 2).

No âmbito das Instituições de Ensino Superior Subtil (2002) acredita que poderão ser concebidas como espaços mistos de formação profissional, onde atividades presenciais e semipresenciais se alternam com atividades a distância, e mediadas pelas TICs (Subtil, 2002). Nessa perspectiva, concordamos que os cursos em Educação a Distância, EAD, existem não só para satisfazer as exigências de qualificação profissional, mas para atender a "grande e diversificada demanda existente e decorrente da obsolescência acelerada da tecnologia e do conhecimento" (Belloni, 2006, p. 5).

Com as transformações e mudanças propiciadas pelas tecnologias emergentes e com a necessidade de ampliar a formação do professor de música, foi instituída a licenciatura em Música, modalidade a distância, da Universidade Federal do Rio Grande do Sul (UFRGS). Criada com base na Resolução CD/FNDE 34/2005, esta licenciatura tem como objetivo formar professores que já atuam na rede básica de ensino, porém sem habilitação para tanto. O curso, que integra o Programa de Formação Inicial para Professores em Exercício nas Séries Finais do Ensino Fundamental e no Ensino Médio, está em sua segunda fase: o "Pró-Licenciatura II" i. Este programa visa democratizar o ensino superior e melhorar a qualidade da educação básica, bem como fomentar o ensino a distância por meio das TICs.

Tendo atuado como tutora itinerante nos pólos de São Félix ${ }^{\text {ii }}$ e Salvador - BA, e sendo o violão meu principal instrumento de trabalho, considero importante ressaltar minhas experiências com os alunos dos referidos pólos através deste relato. Devo lembrar que o curso não tem como intuito a formação de concertistas, mas de professores de música habilitados a profissão. Para tanto, selecionei os alunos que optaram pelo violão na interdisciplina Seminário Integrador, e elegeram o instrumento como suporte para suas práticas educativas e musicais no campo de trabalho.

Na referida interdisciplina, o repertório para violão tem contemplado tanto músicas de tradição européia, quanto canções populares. Trata-se de um conteúdo programático fundamentado na abordagem holística de ensino, pois concebe as duas vertentes da música ("erudita" e "popular") em uma única dimensão, haja vista a inserção cada vez maior do estudo de músicas brasileiras no repertório para violão. A vantagem desta abordagem é que os estudantes têm acesso às músicas que lhes são familiares: oriundas de seus próprios contextos 
sociais, sendo este um fator determinante para a motivação de alunos que querem aprender a tocar violão (Tourinho, 1998). Ao contrário das escolas tradicionais que privilegiam o estudo das músicas de tradição européia, acredito que a escolha do repertório exerce influências significativas sobre os estudantes, pois incentiva a prática coletiva e a aprendizagem colaborativa.

Assim, percebendo a importância da metodologia do ensino coletivo de violão para os alunos do curso, na perspectiva de ampliar a formação dos mesmos, proponho uma reflexão acerca das possibilidades de ensino do instrumento a distância. Acredito na ampliação de propostas para a educação musical nesta modalidade que venham a contemplar o ensino de violão apoiado pelas tecnologias da informação. Mesmo ciente dos desafios existentes para os profissionais da área, seja pelas especificidades da música ou pelas condições de infraestrutura que o próprio país oferece, por exemplo, a dificuldade de acesso a internet banda larga para transmissões de vídeo conferências (Braga, 2009). Por sua vez, defendo o ensino coletivo de violão apoiado pelas TICs por propiciar maior interação entre alunos, professores e tutores na promoção da aprendizagem colaborativa e cooperativa.

\section{ENSINO COLETIVO DE VIOLÃO NA LICENCIATURA}

O ensino de violão na licenciatura em Música a distância da UFRGS que classifico como coletivo, ocorre em duas fases as quais denomino de virtual e presencial. Na primeira fase, o ensino acontece através do ambiente denominado MOODLE (Modular Object Oriented Distance LEarning), que consiste em um software livre utilizado para ajudar educadores na criação de cursos online (Pulino Filho, 2004). Navegando pela plataforma, os alunos têm acesso ao conteúdo das interdisciplinas e aos recursos que buscam assegurar a eficácia da aprendizagem no ensino a distância, tais como: fóruns de discussões, quadro de informações, grupos de atividades coletivas, arquivos e relatórios. Na segunda fase, os alunos contam com a infraestrutura dos pólos: espaços onde acontecem as atividades presenciais e são promovidas as práticas coletivas de ensino do instrumento. São quatorze pólos em vários municípios do país que contam com laboratório de informática com internet, salas de violão, teclado, tutoria, secretaria e midiateca ${ }^{\text {iii }}$.

No pólo de São Félix, os alunos se reúnem diariamente para acessar a plataforma virtual, ler os conteúdos das interdisciplinas, dialogar, discutir e realizar as tarefas. Em Salvador são destinados três dias da semana para os encontros. Desta forma, semanalmente se adiciona uma unidade no MOODLE, ou seja, um novo conteúdo é introduzido para o ensino de violão. O esperado é que os alunos consigam alcançar os objetivos específicos, por exemplo, no final da unidade que contempla o estudo da "Cadência Menor e Levada PopRock", os estudantes devem executar cadências menores, tocar o ritmo ou levada sugerida e as músicas correspondentes. Para tanto, o assunto é amplamente discutido entre os estudantes dos pólos ou por meio de fóruns, ou pelo $m s n$, ou presencialmente, e na tentativa de encontrar alternativas que possam ser aplicadas a execução das músicas, exercícios técnicos dentre as atividades solicitadas.

Sabendo que o MOODLE não é um ambiente específico para o ensino de instrumento, embora disponha de ferramentas úteis que auxiliam no processo de aprendizagem a distância, o curso disponibiliza outro material para o ensino de violão: o E-book violão. Trata-se de um livro em formato digital contendo ilustrações, fotos, vídeos e áudio ${ }^{\text {iv }}$. Nele os alunos podem 
assistir aos vídeos e perceber, por exemplo, como o ritmo está sendo executado, ou se há alguma técnica específica que facilite a execução das músicas estudadas. Assim, nas unidades disponibilizadas na plataforma os alunos obtêm os procedimentos para a efetivação da prática do violão, e com o E-book eles podem ler as partituras, visualizar acordes (inclusive em animação), bem como assistir aos vídeos. Portanto, os materiais se complementam fornecendo subsídios para que os estudantes consigam interpretar o conteúdo e tocar o instrumento sem que o professor esteja presente, como ocorre no ensino convencional.

As interações entre os alunos ocorrem quando trocam informações acerca do conteúdo, ou quando buscam solucionar problemas provenientes das atividades. Para tanto, utilizam os fóruns de discussão ou interagem através do msn (o conhecido Messenger). Vale ressaltar, que tanto em São Félix quanto em Salvador os estudantes ainda não usavam webcam em suas conversas porque os pólos ainda não contavam com este recurso no período que exerci tutoria. Então, os alunos se encontravam nos pólos para discutir os problemas e apenas quando precisavam recorriam ao serviço de tutoria. Nisto consiste o ensino e aprendizagem de violão a distância: em saber trabalhar em grupo utilizando cada vez mais as ferramentas tecnológicas e buscando adequá-las ao ensino de música e suas especificidades.

Até o momento desta experiência os alunos dependiam da estrutura dos pólos, porque muitos ainda não contavam com computadores e internet em suas residências para a realização de suas as atividades. Quando se trata de tocar violão corrigindo a postura, executar músicas ou encontrar técnicas para a execução de peças, os alunos também recorriam ao pólo para a prática do instrumento. $\mathrm{O}$ que se espera, porém, é que eles possam interagir com os colegas através de ferramentas tecnológicas, sem a presença de todos os estudantes no mesmo espaço físico. Um exemplo sugerido era fazer com que o grupo desenvolvesse alguma atividade de execução rítmica com base no conteúdo proposto e através de vídeo conferência.

Neste aspecto, identifico algumas diferenças entre o ensino coletivo de violão convencional e a distância. No primeiro a presença do professor junto aos alunos é suficiente para promover a aprendizagem por meio das interações, porque eles não estão separados fisicamente pelo tempo e espaço. No segundo caso, porém, são as tecnologias empregadas que deverão suplantar a separação entre os mesmos. Assim, conforme Moore (2002) na modalidade a distância é necessário que sejam determinadas técnicas e estratégias específicas para o ensino e aprendizagem, a fim de suprir a separação entre aluno e professor, já que se diferenciam das práticas da educação convencional. Por sua vez, as estratégias devem favorecer a aprendizagem com uso das tecnologias de comunicação mais sofisticadas e tenderão a propiciar a tão almejada interação entre alunos e professores (Moore, 2007).

Desta forma, um dos desafios no contexto atual de educação brasileira é desenvolver competências relacionadas "à cultura técnica e à capacidade de integrar materiais pedagógicos em suportes tecnológicos mais sofisticados, especialmente a multimídia" (Belloni, 2006, p. 87). Cultura técnica diz respeito ao domínio de técnicas ligadas ao audiovisual e à informática, indispensáveis em situações de ensino e aprendizagem (Belloni, 2006). Diante da necessidade de propiciar maior interação entre professores, alunos e tutores defendo que os estudantes também devem ser incentivados ao exercício constante para aprender a lidar com os suportes tecnológicos mais sofisticados, por exemplo, a multimídia. Sendo válida ainda a possibilidade de aplicar estes suportes em práticas coletivas de violão a distância.

Acredito que e-mail, listas, fóruns de discussões, msn e skype são importantes porque permitem flexibilizar a interação ${ }^{\mathrm{v}}$ se comparada à fixidez dos programas informáticos (Belloni, 2006) e são ferramentas úteis para o ensino de música. Ressalto ainda que esta situação, apesar de ser comum nos pólos onde atuei nem todos os alunos possuíam computadores com internet 
em suas residências, o que explica a presença da maior parcela deles nos pólos. Assim, é preciso estimular sempre a interação entre todos os participantes do curso, buscando cada vez mais a valorização de inteligentes coletivos como defende Lévy (2005). Isto significa, que na era do conhecimento o importante é valorizar o outro de acordo com o leque de seus saberes, ou seja, valorizar a inteligência distribuída e em todas as esferas da vida humana (Lévy, 2005).

Neste cenário de aprendizagem a distância destaco o professor tutor, que é um profissional e docente dotado de duas características essenciais: o domínio do conteúdo técnico e científico e a habilidade para estimular os participantes a buscarem respostas (Gonzalez, 2005). No entanto, o papel do tutor vai além da solução dos problemas que emergem, porque "investe na construção de uma relação de respeito e confiança, buscando despertar o amor pelo conteúdo e visando superar os obstáculos encontrados pelo aprendiz" (Gonzalez, 2005, p. 79). É ele o responsável em manter o ambiente o mais prazeroso possível, incentivando a prática coletiva do instrumento e a interação entre os sujeitos. Tais atribuições não o desqualificam do papel de educador, já que o mesmo participa de todo processo de ensino e aprendizagem que inclui: avaliação, a seleção e produção de materiais pedagógicos. Sem contar que, cabe ao tutor auxiliar na prática do instrumento fazendo com que os alunos consigam dominar as técnicas e outros elementos necessários para tocar violão. Concordo com Gonzalez (2005) que, "sozinho o aprendiz caminha vacilante, perdendo o rumo desejado [e] nisso o tutor pode ampará-lo, conduzi-lo e encaminhá-lo" (Gonzalez, 2005, p. 80).

Nesta perspectiva de tutoria trabalhei com os alunos dos dois pólos durante os encontros presenciais, ou por msn e com webcam: quando estive separada deles pelo espaço geográfico. Assim, os aprendizes eram reunidos em formato de círculo como propõe a professora Cristina Tourinho ${ }^{\mathrm{vi}}$ no ensino coletivo e convencional. Segundo a autora "boa parte das atividades podem ser feitas com os estudantes sentados desta forma, na qual se inclui o professor" (Tourinho, 2006). Esta disposição é democrática, porque todos se colocam em posição igualitária e o desenho propicia a visualização de todos os envolvidos. É notório o desenvolvimento de vários alunos com base nesta prática em grupo, porque ao ouvir e visualizar o colega tocando, os aprendizes trocam informações e isto contribui para a construção de conhecimentos musicais.

Para Tourinho (2007), o mito de que o aluno requer exclusividade durante o ensino tutorial contrapõe a crença do ensino coletivo. Ao contrário do que se concebe, no ensino coletivo é possível compartilhar tanto conhecimento quanto espaço sendo a interação e a diferença componentes importantes do aprendizado (Tourinho, 2007). Desta forma, a ocupação dos educadores já não se concentra mais em comprovar a eficácia da metodologia, mas em sistematizar os materiais a fim de fornecer subsídios aos aprendizes em distintas situações de ensino e aprendizagem de violão. Assim tenho a convicção de que:

O ensino em grupo possibilita uma maior interação do indivíduo com o meio e com o outro, estimula e desenvolve a independência, a liberdade, a responsabilidade, a auto-compreensão, o senso crítico, a desinibição, a sociabilidade, a cooperação, a segurança e, no caso específico do ensino da música, um maior desenvolvimento musical como um todo (Cruvinel, 2005, p. 80).

Em ambos os pólos onde atuei pude verificar a eficácia da metodologia coletiva, embora reconheça que ampliar o ensino através do uso de ferramentas tecnológicas que auxiliem neste processo de aprendizagem seja de suma relevância para o desenvolvimento de novas competências. Quanto aos vínculos de amizade estabelecidos entre tutor e estudantes 
acredito que são fatores que motivam e incentivam a prática coletiva do instrumento, bem como a construção de conhecimentos musicais. Também vale destacar a importância do professor responsável pela elaboração do conteúdo programático, é ele que designa funções junto a sua equipe para a produção de materiais, discuti a ocorrência de problemas, busca soluções, avalia e participa de todo processo de ensino e aprendizagem.

Assim sendo, a metodologia do ensino coletivo tende a se alargar cada vez mais pela possibilidade de inserção e utilização de novos recursos tecnológicos e que possam ser aplicados no ensino de violão a distância. Considerando que nos pólos onde atuei, nem todos os alunos envolvidos possuíam uma infraestrutura desejada e adquirir computadores com internet e suporte multimídia ainda é um processo demorado para muitos deles. Por outro lado, as iniciativas dos que coordenam esta licenciatura são encorajadoras para repensar as atuais estruturas de educação musical no Brasil, bem como suscitar a criação de novos cursos de Música a distância na tentativa de atender demandas que necessitam ingressar em universidades, porém sem condições para tanto.

\section{COLABORAÇÃO E COOPERAÇÃO NO ENSINO DE VIOLÃO A DISTÂNCIA}

Com base na experiência do ensino de violão a distância percebo que a intenção é fazer com que os alunos sejam capazes trabalhar em grupo e gerenciar cada vez mais seus próprios estudos. Tendo em conta o formato dos materiais virtuais de ensino e a maneira como são concebidos, o intuito é que os alunos consigam dominar o conteúdo produzindo conhecimentos musicais e desenvolvendo competências através do exercício da autonomia. Como esclarece Belloni (2006) sobre a tão almejada autonomia, segundo ela diz respeito ao desenvolvimento das capacidades de autoaprendizagem do alunado, que não se trata apenas de introduzir as tecnologias no curso, mas de reorganizar todo processo de ensino. Ressalto, porém, que a pretensão não é centrar o ensino no professor ou no aluno, mas que o trabalho coletivo a distância também incentive a prática de uma cultura de autoaprendizagem. Em concordância com Belloni (2006), este tipo de estrutura é importante, principalmente, porque no Brasil "os níveis de cultura geral e de escolaridade são, de modo geral, pouco elevados e [...] a escola não instrumentaliza os jovens para o exercício da autoaprendizagem" (Belloni, 2006, p. 106).

Desta forma, as interações propiciadas pelo uso das ferramentas tecnológicas e unidas às práticas em grupo determinam novas possibilidades de aprendizagem. Tomando como exemplo o modelo presencial da metodologia em grupo, Tourinho (2004) diz que os alunos que já possuem habilidade com o instrumento podem ajudar aqueles que ainda não conseguem tocar. Assim, na aprendizagem colaborativa todos aprendem com todos (Tourinho, 2007). Neste caso, tenho aplicado este princípio com os estudantes de violão nos pólos, porque mesmo com turmas reduzidas há sempre algum aluno que já toca o instrumento, o que tem colaborado para a aprendizagem dos demais.

Estudantes que possuem alguma experiência com o estudo do instrumento são tomados como referência para aqueles que ainda estão iniciando. Belloni (2006) sustenta que, neste cenário de interações a distância, os alunos devem ser capazes de trabalhar em equipe e de modo cooperativo (Belloni, 2006). A cooperação diz respeito às técnicas de aprendizagem na qual os estudantes ajudam-se mutuamente atuando como parceiros entre si mesmos e também com os professores, visando obter conhecimentos a partir de um processo de construção social 
(Campos et al, 2003; Gonzalez, 2005). Para Tourinho (2006) é na aprendizagem cooperativa que o professor tem a oportunidade de lidar com as diferenças dos seus alunos de forma positiva, buscando alcançar a tão sonhada homogeneidade entre eles, fator muito comum no ensino tradicional.

Por outro lado, Gonzalez (2005) ressalta que a efetiva realização do trabalho cooperativo requer a divisão de tarefas entre os participantes, a fim de solucionar os problemas. Portanto, isto sugere a hierarquização entre os membros do grupo. Considerando a experiência em São Félix e Salvador, posso afirmar que embora existindo uma hierarquia entre professores, tutores e alunos no âmbito desta licenciatura, esta não constitui um empecilho para o ensino de violão. Todos cooperam de alguma maneira para a aprendizagem dos estudantes, como o trabalho dos professores que se ocupam com a elaboração de materiais virtuais como o E-book. Assim, por exemplo, os vídeos devem fornecer informações bastante detalhadas da posição das mãos do violonista, ou da sua postura para facilitar o entendimento dos alunos que aprendem a distância.

A proposta da interdisciplina Seminário Integrador, violão, vai além da hierarquia dos seus membros, fazendo uso disto apenas para obter melhor organização, planejamento e criar estratégias para favorecer a aprendizagem colaborativa. Vale esclarecer novamente que o termo colaboração é compreendido como um conjunto de técnicas de aprendizagem para utilização em grupos estruturados, ou estratégias de desenvolvimento de competências mistas na qual cada indivíduo é responsável pela sua aprendizagem e pela aprendizagem dos demais envolvidos (Ribeiro; Sousa Júnior, 2008). Com os alunos de violão funciona da seguinte forma: o professor elabora com a equipe o conteúdo da interdisciplina, o tutor acompanha os estudantes diretamente unindo teoria e prática e fazendo valer o ensino em grupo, por sua vez os alunos colaboram entre si e com os outros para que se efetue a aprendizagem. $\mathrm{Na}$ modalidade a distância defendo que:

O computador disponibiliza o suporte à comunicação e colaboração, provendo assistência ao processo de coordenação, permitindo a criação de situações impossíveis no mundo real, rastreando as ações dos membros do grupo, que podem ser utilizadas para a melhoria de estratégias de soluções de problemas, e estimulando os processos mentais de aquisição do conhecimento (Campos et al, 2003, p. 51).

Assim, nos ambientes de aprendizagem por colaboração e apoiados por computadores, considero que "as tecnologias colaborativas permitem a construção de formas comuns de ver, agir e conhecer; ou seja, são ambientes que habilitam indivíduos a se engajarem na atividade de produção do conhecimento compartilhado" (Campos et al, 2003, p. 51). Portanto, saber trabalhar com os recursos tecnológicos disponíveis é o que se pretende para o ensino de violão a distância, de modo que sejam ampliadas cada vez mais as possibilidades de interação entre alunos, professores e tutores.

\section{CONSIDERAÇÕES FINAIS}

Nos pólos de São Félix e Salvador as interações entre os estudantes contribuem para a construção de conhecimentos musicais, bem como para efetivar a aprendizagem colaborativa e cooperativa. Após a leitura integral do conteúdo a prática musical acontece quando se executa ao violão as atividades propostas. Para tanto, agrupo os estudantes em formato de círculo e 
trabalhamos os seguintes aspectos: leitura de notação musical, formação acordes, ritmos, músicas e peças do repertório tradicional, dentre outros. No entanto, esta também é uma prática possível mediante o auxílio de webcam numa vídeo conferência, se esta ferramenta estivesse disponível nos pólos no período de minha atuação. Por exemplo, realizei algumas tutorias em meu computador e através da internet pelo msn e com webcam junto aos alunos de São Félix, quando eu estava em Salvador. Ressalto, porém, que os computadores dos dois pólos até então não contavam com webcam para que eu pudesse visualizar os estudantes, mesmo assim os alunos conseguiam ver minhas imagens e interagíamos através do diálogo escrito.

Quanto ao repertório selecionado, este engloba canções populares com acompanhamento e também peças tradicionais. Sendo assim, o ensino de violão é desenvolvido com base na abordagem holística (sem a separação dicotômica popular e erudito), tal fato tem motivado os estudantes ao estudo do instrumento, porque já estão familiarizados com as músicas do próprio contexto sociocultural. Deste modo, os estudantes cantam e tocam ao mesmo tempo, ouvindo seus colegas e a si próprios. Os que não cantam ficam atentos e depois tentam acompanhar os outros colegas, assim percebo que todos se esforçam para superarem dificuldades de ordem técnica ou de afinação para o canto.

A cooperação no ensino de violão ocorre quando o professor e sua equipe organizam o conteúdo programático e buscam alternativas inteligíveis para que os estudantes compreendam os materiais virtuais disponíveis. Desta forma a metodologia em grupo é eficaz tanto nos encontros presenciais, quanto a distância e apoiada pelas ferramentas tecnológicas, mesmo com os pólos em processo de estruturação e os estudantes aprendendo a dominar tais ferramentas. O serviço de tutoria também é importante para esclarecer dúvidas buscando unir teoria e prática, bem como motivar os alunos. Assim, considerando os aspectos levantados acredito cada vez mais nas possibilidades do ensino coletivo de instrumento a distância e apoiado pelas TICs, e na aprendizagem colaborativa e cooperativa propiciada pelas interações entre alunos, tutores e professores.

\section{NOTAS}

\footnotetext{
${ }^{2}$ BRASIL. Pró-Licenciatura. $\quad$ Disponível em: <http://portal.mec.gov.br/seed/index2.php?option=com_content\&do_pdf=1\&id=179> Acesso em: 22 out. 2008.

${ }^{3}$ Município do Estado da Bahia, situado a 110 km de Salvador, às margens do Rio Paraguaçu.

4

Disponível em:

<http://www.prolicenmus.ufrgs.br/index.php?option=com_content\&view=article\&id=13\&Itemid=27> Acesso em: 23 out. 2008.

${ }^{5}$ Disponível em: <http://caef.ufrgs.br/produtos/ebook_violao/pre8/index.html>. Acesso em: 14 out. 2008

${ }^{6}$ No contexto deste relato, interpreto o termo interação como um "encontro de dois [ou mais] sujeitos - que pode ser direta ou indireta (mediatizada por algum veículo técnico de comunicação, por exemplo, carta ou telefone)" (Belloni, 2006, p. 58).

${ }^{7}$ Professora responsável pela interdisciplina Seminário Integrador, Violão, na licenciatura em Música, EAD, da UFRGS.
} 


\section{REFERÊNCIAS BIBLIOGRÁFICAS}

BARRETO, Robson. Choro: uma abordagem técnica instrumental. In: XVI ENCONTRO ANUAL DA ABEM, 16., 2007, Campo Grande. Anais. Campo Grande: ABEM, 2007, p. 1 11 .

BELLONI, Maria Luiza. Educação a Distância. 4. ed. São Paulo: Autores Associados, 2006.

BRAGA, Paulo David Amorim. Oficina de Violão: Estrutura de Ensino e Padrões de Interação em um Curso Coletivo a Distância. 2009. 320 f. Tese (Doutorado) - Curso de Música, Departamento de Programa de Pós Graduação em Música, UFBA, Salvador, 2009.

BRAGA, Paulo David Amorim ; RIBEIRO, Giann M. Estruturação de um curso de violão a distância. In: XVI ENCONTRO ANUAL DA ASSOCIAÇÃO BRASILEIRA DE EDUCAÇÃO MUSICAL E CONGRESSO REGIONAL DA INTERNATIONAL SOCIETY FOR MUSIC EDUCATION NA AMÉRICA LATINA, 2007, Campo Grande MS. Anais. Campo Grande: Editora da UFMS, 2007.

BRASIL. Resolução/CD/FNDE/N $\mathbf{3} 4$, de 9 de Agosto de 2005. Disponível em: $<$ http://www.fnde.gov.br/home/index.jsp?arquivo=legislacao.html\#prolicenciatura $>$ Acesso em: 15 out. 2008.

CAMPOS, F. et al. Cooperação e aprendizagem on-line. Editora DPA. Rio de Janeiro, 2003.

CRUVINEL, Flávia Maria. Educação musical e transformação social: uma experiência com ensino coletivo de cordas. Goiânia: Instituto Centro-Brasileiro de Cultura, 2005.

O ensino do violão: estudo de uma metodologia criativa para a infância. Goiânia: Monografia de especialização em Música Brasileira no Século XX. Escola de Música e Artes Cênicas da Universidade Federal de Goiás, 2001, 235p.

FIREMAN, Milson Casado. O repertório na aula de violão: um estudo de caso. 2006. 150 f. Dissertação (Mestrado em Música). Escola de Música, Universidade Federal da Bahia, Salvador. 2006.

GONZALEZ, Mathias. Fundamentos da Tutoria em Educação a Distância. São Paulo: Avercamp, 2005. 
LÉVY, Pierre. A inteligência coletiva: por uma antropologia do ciberespaço.Tradução de Luiz Paulo Ronanet. 5. ed. São Paulo: Loyola, 2007.

MOURA, Risaelma de J. A. Desenvolvimento Musical de Alunos da Disciplina Instrumento Suplementar (Violão). 2007. 168 f. Dissertação (Mestrado em Música). Escola de Música da Universidade Federal da Bahia, Salvador. 2007.

PULINO FILHO, Athail Rangel. Introdução ao Moodle. Módulo I. Disponível em: $<$ http://www.moodle.uneb.br/mod/resource/view.php?id=1322>Acesso em: 13 out. 2008.

QUEIROZ, Luis Ricardo S. O ensino do violão clássico sob uma perspectiva da educação musical contemporânea. 2000. 90 f. Dissertação (Mestrado em Música). Conservatório Brasileiro de Música, Rio de Janeiro. 2000.

RIBEIRO, Gilseno de Souza Nunes; SOUSA JUNIOR, Rafael Timóteo de. WEBQUEST: Protótipo de um Ambiente de Aprendizagem Colaborativa a Distância Empregando a Internet . Disponível em: $<$ http://www.abed.org.br/publique/cgi/cgilua.exe/sys/start.htm?UserActiveTemplate=4abed\&in foid=110\&sid=124>. Acesso em: 26 out. 2008 .

SUBTIL, Maria José Dozza. Considerações Gerais Sobre a Educação a Distância a Partir da Perspectiva de Alguns Autores. Informática na Educação: Teoria e Prática, Porto Alegre, v. 05, n. 01, p.25-30, maio 2002.

$<$ http://www.seer.ufrgs.br/index.php/InfEducTeoriaPratica/article/view/5234/3491>. Acesso em: 12 out. 2008.

TIAGO, Roberta Alves; PERDOMO, Ana Paula Silva Aguiar. "Um cantinho um violão...": Uma experiência com a abordagem sócio-cultural da Educação Musical e com o Modelo T(E)C(L)A (Swanwick 1979) no Conservatório Estadual de Música Cora Pavan Capparelli, Uberlândia - MG. In: XIII ENCONTRO ANUAL DA ASSOCIAÇÃO BRASILEIRA DE EDUCAÇÃO MUSICAL, 13., 2004. Rio de Janeiro: ABEM, 2004. p. 940 - 947.

TOURINHO, Ana Cristina Gama dos Santos. A motivação e o desempenho escolar na aula de violão em grupo: influência do repertório de interesse do aluno. 1998. Dissertação (Mestrado em Música). Escola de Música da Universidade Federal da Bahia, Salvador. 1998.

Ensino Coletivo de Violão e Princípios da Aprendizagem Colaborativa. In: I ENCONTRO NACIONAL DE ENSINO COLETIVO DE INSTRUMENTO MUSICAL, 1, 2004. 1., Goiânia: ENECIM, 2004. p. 37 - 43. 
Ensino coletivo de violão: proposta para disposição física dos estudantes em classe e atividades correlatas. Anais do Seminário Nacional de Arte e Educação, v. 20, p. 31-35, 2006.

Ensino Coletivo de Instrumentos Musicais na Escola de Música da UFBA: Inovando a Tradição, Acompanhando o Movimento Musical do Brasil. In: OLIVEIRA, Alda de; CAJAZEIRA, Regina. Educação Musical no Brasil. Salvador: Sonare, 2007. Cap. 34, p. 256-264.

ii

iii

iv

v

vi 